\title{
IID冋 Estrategias enunciativas en el discurso irónico: un artículo de opinión de José-Ignacio Cabrujas
}

\section{TERESA ESPAR}

UNIVERSIDAD DE LOS ANDES, MERIDA, VENEZUELA

\begin{abstract}
RESUMEN, En el análisis semántico y semiótico de] discurso [Escuela de París y escuela francesa de análisis del discurso), cualquier unidad micro o macro-estructural puede consrituir un punto de partida esclarecedor para reestablecer la arquitectura del sentido. Partiendo del análisis de los lexemas, responsables de la consticución de las isotopias temáticas y figurativas (Greimas, 1968) en su condición de unidades semánticas mínimas del sisrema de la lengua, propondremos la explicación y la interpretación de un articulo de opinión de José-Ignacio Cabrujas (Caracas, 1937 1995). El análisis de los mecanismos de construcción del simulacro discursivo que provienen de la instancia de la enunciación (Benveniste, Greimas y Courtés) considerada como unidad macro-estructural, permitirá un acercamienco a los recorridos laberínticos del decir, que al mismo tiempo represenca nuestras formas de vida (Wîtgenstein), aserta, manipula, accúa, nos hace sentir (Scarle, Austin. Ducrot, Greimas y Fontanille) y nos induce a la sonrisa de la distancia irónica o al gesto amargo del sarcasmo. La densidad semántica del discurso irónico nos servirá de pretexto para mantener nuestra posición critica ante las dificultades del micro-análisis semántico del discurso.
\end{abstract}

PALABRAS CLAVE: sentido -isotopias temáticas- estrategias enunciasivas-discurso irónico- crítica micro-análisis semántico.

RESUMO. Na análise semântica e semiórica do discurso (Escola de Paris e Escola Francesa de Análise do Discurso), qualquer unidade micro ou macro-estrurural pode construir um ponto de parrida esclarecedor para resrabelecer a arquiterura do sentido. Partindo da análise dos lexemas, responsáveis pela constituição das isotopias temáticas e figurativas (Greimas, 1968 ) na sua condiçăo de unidades semânticas mínimas do sistema da língua, ofereceremos a explicação e interpretaçảo de um arrigo de opinião de José-Ignacio Cabrujas (Caracas, 1937-1995). A análise dos mecanismos de construçáo do simulacro discursivo que provèm da instancia da enunciação (Benveniste, Greimas e Courtés) considerada como unidade maço-estrutural, permitirá uma aproximação aos percursos labirfnticos do dizer, que ao mesmo tempo representa as nossas formas de vida (Wittgenstein), afirma, manipula, atua, nos faz sentir (Searle, Austin, Ducror, Greimas y Fontanille) e nos leva ao sorriso da distancia irônica ou à expressão amarga do sarcasmo. A densidade semântica do discurso irônico nos servirá de pretexro para manter a nossa posição crítica frente às dificuldades da micro-análise semânrica do discurso.

PALAVRAS CHAVE: sentido -isotopias temáticas- estrategias enunciativas -discurso irônico- crírica micro-análise. 
ABSTRACT. In the semantic and semiotic analysis of discourse (Paris School and French School of Discourse Analysis), any structural micro or macto unit may constitute a starting point to clarify and reconstruct the architecture of sense. From the lexemes that are responsible for the constitution of thematic and figurarive isotopies (Greimas, 1968) in their condition of minimal semantic units of the language system. we propose the explanation and interpretarion of an opinion article by JoséIgnacio Cabrujas (Caracas, 1937-1995). We shal) analyse the construction mechanisms of the discoursal simulation derived from the instance of enunciation (Benveniste, Greimas and Courtes), which is taken as the macro-structural unit. in this way, we will allow approach the laberynthic paths of saying which, at the same rime represent our forms of living (Wirtgenstein), asserting, manipulating, acting, making us feel (Searle. Austin, Ducror, Greimas and Fonteille) and induce us ro smile at the ironic distance or the bitrer gesture of sarcasm. The semantic density of this ironic discourse will serve as a precext to maincain our critical position with respect to the difficulties presented by the semantic micro-analysis of discourse.

KEY WORDS: sense-thematic isotopies-enunciation strategies-ironic discourse- criticism of semantic micra-analysis.

\section{Preludio}

Quisiéramos evocar, previamente, uno de las últimos escritos de A.J.Greimas citado por Bernard Quemada (1993) en Hommages à Greimas y con el cual quiso honrar su memoria como el gran descodificador de la semiosis que fue. Léloge du mot nos recuerda la umwelt socio-cultural de las entidades lingüísticas mínimas portadoras de sentido:

Le mot -et la configuration qui l'accompagne- n'est pas seulemene un objet de discours, il est à lui seul un objer-discours, $c$ est à dire un objer sémiorique, à la fois objer de connaissance er objer complexe dont les arciculations internes, clotûrées d'une certaine manière, lui conferent un staur d autonomie. Entre la casquerte de Charles Bovary et un tableau de Paul Klée, it doit y avoir la place pour l'article du dictionnaire. Le prope de ces objets discursifs - car ils relèvent de l'ordre de l'usage- ese de posséder une organisation en soi qui lui grantit sa clotûre er dont la complexité provient à la fois des incerférences er des imbrications des codes er mycro-systèmes linguistiques qui y sont engagées et les traces participatives que l'on y décelle. (...) Peu importe d'ailleurs l'origine de cet univers dès que l'on admer que la configuration du mot baigne dans l'immense Umwelt sémio-culturel où elle peur puisser à volonté. C'est le pouvoir de convocarion de cet univers qui est en jeu lorqu'il s'agit de comprendre le fonctionnement du dictionnaire (p. 56-57).

A partir de esta evocación nos permitiremos afirmar que si una palabra puede encerrar en ella misma un discurso completo, un texto extenso se presentará siempre a los ojos del invescigador como un desafio a su acrividad explicariva, siempre que se lo plantee como un universo de sentido. Cualquier entidad por pequeña que sea puede esconder en ella pasiones $y$ tensiones (Delorme, 1987), lo dicho o lo denegado que podrá ser manifestado bajo otro aspecto, de acuer- 
do sólo con la intencionalidad omnipotente de un sujeto de enunciación, proto-actante existencial antes de serlo fenomenológico, que organizará su propio simulacro de existencia, inteligibe siempre y siempre sensible.

Si una palabra puede ser un discurso complejo, de la misma manera un discurso puede ser una sola palabra o dos o tres en expansión, que al ser narradas, tienen el poder de convertirse en simulacro existencial de todas aqueIlas referencializaciones oficciones que el imaginario humano con su poder semiósico mediador, alcance a convocar en el texto; de este modo cualquier fragmento de discurso puede ser aprehendido como el espacio condensado en el que podrían manifestarse los más diversos y densos efectos de sentido con sus valores semánticos implícitos o presupuestos; esos efectos aspectuales o estéticos, morales o irónicos, racionales o paradójicos tendrán forma semiótica y se presentarán organizados en un trayecto generarivo, llamado a representar múltiples formas o estilos de vida a través de los juegos de lenguaje (Wittgenstein, citado por Vernant, 1997). Es suficiente para ello con que un sujeto enunciante apasionado, moralista, sarcásrico y barroco, come en sus manos su competencia comunicativa para que una entidad semiótica cualquiera que ésta sea, manifieste los puntos de vista que las valencias de sentido le ofrecen y haga girar -como un caleidoscopio- el famoso recorrido generativo de la significación.

De un texto calidoscópico, irónico, ético, retórico y barroco quisiéramos tratar de dar cuenta para intentar mostrar su arquitectura, parriendo inicialmence de las palabras en lengua -en el diccionario-para contemplarlas más carde, después de haber pasado por la instancia de la enunciación, convertidas en perfume timico (Greimas et Fontanille, 1991) y en perfume irónico, si se nos permite ampliar los perfumes textuales a esa sobreabundancia de sentido que sería el humor, con sus rodeos distanciadores típicos y específicos.

\section{1. "Hors du texte point de salut", con algunos problemas de método}

Seducida siempre por el principio de inmanencia, quisiera en este inicio intentar dar cuenta de lo que el texto manifiesta en su construcción como simulacro de un universo de valores -al mismo tiempo memoria colecriva y praxis enunciativa- de un actante individualizado que se multiplica en $e l$ mismo y el Otro (Ricoeur, 1990) del presente y del transcurrir, en el momento de escenificar una sanción social concra la vida política democrática de Venezuela durante un periodo que se extiende a lo largo de los últimos veinte años.

Al mismo riempo, $y$ después de haber seguido los trabajos del Grupo greimasiano en su centro parisino y sobre rodo en la diáspora latinoamericana desde 1972, quisiera plantear una reflexión que me conducirá a manifescar mis 
dudas y mis perplejidades y a reconocerme invadida de ignorancia sobre los asuntos de la semiótica en tanto que mediación -tercer mundo- entre el mundo físico (mundo 1) y las representaciones psicológicas (mundo 2) (Rastier, 1991). Esta declaración de ignorancia está implícica además en una aseveración que se ha hecho recurrente entre nosotros y que nos conduce a acepcar que existen textos resistentes al análisis. Plantear esta resistencia de los textos, al mismo tiempo que es un reconocimiento del límite del conocimiento humano, implica la acepración de la nacuraleza rebelde al análisis, de ese mundo 3 que sería el mediador entre el mundo 1 y el mundo 2. Lo propio de la mediación es $-y$ me permito aquí metaforizar el título del libro de Ricoeur anteriormente citado- de ne pas être soi-méme sino en la medida de estar entre el uno y lo otro -être entre l'un et l'autre- que explicaría la tensitividad de lo semiótico como algo intrínseco y específico, perteneciente a su propia naturaleza, $y$ por lo tanto, a su modalidad de presencia en tanto que significación inmanente. Convertir en perceptible y sensible el mundo natural $y$ el imaginario humano -no importa nunca que ínfima parte de ese mundo y de lo real vivido- sigue siendo siempre una operación tan compleja y desviada que intentar dar cuenta de ella -explicar y comprender- no puede hacerse sino corriendo el riesgo al que tienen que enfrentarse todos aquellos que conforman el $c l u b$ de los descodificadores significantes.

Y una vez propuesto este savoir partagé a modo de barricada, seguiremos ahora un camino clásico que, partiendo de los lexemas, se oriente hacia las macro-unidades, para tracar de destacar en la práctica analírica de un texto cerrado, aquellos conocimientos adquiridos ya hace tiempo, la operatividad $y$ ganancia de inteligibilidad de los avances recientes $y$, en fin. la resistencia al análisis de los objetos semióticos, una resistencia compartida entre la aprehensión teórica del juego semiótico y el método analítico con su resultado que sería un ensayo semiórico.

En efecto, una observación que podrla parecer impertinente, nos ha enseńado a propios y extraños, que los análisis semióticos, incluso cuando son impecables desde el punto de vista reórico-metodológico, resultan poco operativos y sobre todo poco eficaces desde el punto de vista de su función comunicativa $y$ pedagógica, con lo cual nos hemos ganado la fama de secta de iniciados; muchas de las polémicas con otros lectores de signos no se refieren ranto a la comprensión teórica de los fenómenos de la significación o a sus relaciones con su vocación cientifica, sino justamente, a ese efecro de sentido can extendido en nuestros medios naturales de expansión. Al lado de los desafios que la semiótica plantea, de esos grandes desafíos, deberíamos cambién intentar ser rigurosos $y$ eficaces para ser comunicativos y para significar, puesto que somos mediadores en el mundo de la mediación.

Cuando hablo, entonces, de resistencia, hablo no solamente de la resistencia de los discursos complejos a ser explicitados, sino cambién de la dificultad que existe para que sean recibidos y leidos a través de nuestra mediación ex- 
plicariva y confieso que en mi experiencia esta realidad no ha sido para nada un obstáculo despreciable. ¿̨odríamos decir, sirviéndonos de una antifrase, que algunas veces se vería el trabajo de los semióticos como si un ratón pariera una montaña? Y planteándolo de una manera menos irónica: se trata de dar cuenta de la complejidad de una unidad de sentido cualquiera, que es directamente comprensible desde el punto de vista de su manifestación comunicativa o estética, en el momento en que debe ser mostrada como un conjunto de redes articuladas. Si bien es cierto que esta complicación perrenece a la naturaleza misma del objero, podemos plantearnos, sin embargo, la necesidad de discutir también acerca del método, no de análisis, puesto que el objeto debe ser aprehendido en su complejidad arciculada, mereológica y discontinua, sino de la manera de dar cuenta de la comprensión de los valores significantes en un trabajo de invescigación y de su puesta en discurso.

Echar una mirada hacia los dominios de las ciencias experimentales podría servir de punto de reflexión, sobre todo cuando practicamos micro-análisis del rexto: el camino de la investigación y de la experimentación es largo y fastidioso; los estudios de los elementos en las biociencias, por ejemplo, se están convirtiendo en una realidad cada vez más sofisticada y microscópica. Células y moléculas en combinaciones estables o inestables, de acuerdo con sus funciones, son estudiadas, analizadas y comprobadas pero el ensayo cienrífico es corro, preciso y eficaz cuando se han producido resultados. Se nos plantea de esta manera un problema de método, de escritura, en relación con los hallazgos sobre la semiosis cuyos componentes hererogéneos y múltiples deberían ser previamente analizados a nivel microscópico en laboratorio, para no perder las ganancias en adecuación e inteligibilidad que el estudio inmanente del discurso proporciona, y evitar así caer en el riesgo de parecer especulativos o impresioniscas cuando tomamos como objeto de reflexión y de investigación, entidades sospechosas de contaminar de ontologismo o metaficisismo los resultados presentados. En efecto, la manifescación de lo noumenal a cravés de lo fenomenal, puede muy bien ser puesta en analogía con la presencia de seres reales y de mundo real, en los que la apariencia de cada entidad se muestra como un continuo que oculta lo compuesto, lo estructurado y lo discontinuo accesible ahora gracias, por ejemplo, al microscopio electrónico. Pero la analogía propuesca debe detenerse en este punto, debido a la naturaleza diferente de los objetos del mundo físico comparados con los objetos del mundo semiótico y se refiere únicamente a la micro-composición estrucrural oculta, opuesta a la fenomenología manifesrada de los objetos del mundo. Sólo los objetos significantes cumplen con la condición de esconder significados, sensaciones $y$ pasiones bajo su soporte material. Los significanres semióticos no pueden ser disociados sino gracias al artificio racionalista de la reconstrucción axiomácica de sus contenidos, $y$ lo racional no es perceptible sino, justamente, a través de sus materiales significantes que no son separables ya que la sustancia significante resulta vacía sin su significado, como en 
una suerte de contra-transubstanciación. Una molécula puede ser observada y descrita, pero una entidad semiótica se debe proponer como una supuesta unidad que forma parte de un trayecto -recorrido generativo, por ejemplotambién imaginado y también construido.

De hecho, el problema analítico de lo semiótico es como la semiosis: una mediación de las mediaciones a través de los meandros sinuosos que construyen los discursos perceptibles pero también sensibles. Una manera de abordarlo es la de determinar qué unidades mínimas significativas son las responsables de la conformación de una isotopía temática que responda a la pregunta: ¿de qué trata el texto?

\section{Lexemas en expansión: "corrupción" y "sospecha"}

Estos dos lexemas en diccionario serán urilizados en la praxis enunciativa para significar universos de valores deceptivos. El diccionario les impone previamente esta restricción determinante y tensa, ya que el texto los acoge de principio a fin para construir a través del juego de intricaciones isotópicas, un destino causativo, una relación y una articulación que conduce, por mediación de la ironía y de la intensificación de esta ironía que es el satcasmo, a la manifestación de una configuración pasional como reflejo y sensación de una experiencia presentada como una forma de vida, es decir, como algo vivido $y$ axiologizado en una sociedad determinada.

Recurrir, para iniciar un estudio inmanence de un texto, al análisis del repertorio léxico, nos parece necesario debido a que la isotopía temática $y$ figurativa marca por su recurso a la redundancia, los limires del universo semáncico escenificado en el discurso y al mismo tiempo suscita en el semiótico una actitud de expectativas de sentido oriencada hacia los simulacros polémicos, disfóricos y pasionales. Desde el inicio, pues, el diccionario contamina de esta manera al analisca.

El diccionario define corromper como un rérmino que construye sentidos en la esfera de lo físico, de lo psicológico y de lo ético, pero el sema nuclear que se puede extraer de un recorrido narrativo común a todas esas recurrencias, sería el de la [degradación] a partir de una transformación de estado: alterar descomponiendo. En el sentido moral de alterar lo que está sano y honesto en el alma, el diccionario lo acerca a términos disfóricos y aspectualizados hacia la intensificación semántica como envilecer, desnaturalizar, depravar, pervertir, codos ellos de naturaleza transiciva. La definición de este lexema en diccionario implica un programa de destinación degradante y deceptiva que presupone un destinador sujeto que actúa como manipulador-transformador de los objetos del mundo y unos destinatarios manipulados, considerados como actores de unas actuaciones y unos sentimientos, que los conducen hacia la pérdida de valores éticos o de otra naturaleza. 
En este recorrido significante la comprión, en su calidad de sustantivo, sería un resultado, un rérmino y por lo tanto el estado final de un proceso de transformación negariva que implica, desde el punto de vista rensivo, una continuidad y una potencialidad deteriorante, como valencia de sentido.

Una interpretación, quizás simplificadora, nos permitiría considerar el diccionario como un enorme depósito de sombras de valor (Greimas y Fontanille, 1991) mil veces realizadas pero que se conservan como memoria histórica y social para manifestarse en el discurso en forma de configuraciones textuales en cada una de sus apariciones nuevas y creativas, dispuestas a surgir como significaciones discursivas obedeciendo al impulso de los sujetos de enunciación; los repertorios léxicos considerados como objetos potenciales serán entonces los útiles adecuados para producir nuevos bricola.

Hemos elegido la corrupción como punto de partida para juscificar la postura epistémica del gran protagonista del discurso que es el sujeco de la enunciación; la sospecha y la corrupcción, sin embargo y en principio, no pertenecerían a un mismo universo semántico, $y$ es preciso justificar su comparecencia en nuestro camino de búsqueda. La sospecha no es una actuación exteroceptiva de un destinador, sino una pasión del sujeto de naturaleza propioceptiva. En el texto objeto de análisis es la marca pasional y cognoscitiva de la instancia de la enunciación, presentada como la modalización contaminante de la actividad del actante observador del recorrido de la corrupción.

El diccionario define sospecha como una conjetura que obliga a atribuir a alguien acciones $o$ intenciones condenables. Se craca de una configuración modal compleja del destinatario relacionada con su posición existencial como actante juez; implica una duda, en primer lugar, encendida en su sentido de creer-no-poder-ser y una transformación epistémica -una incertidumbreque se desliza hacia el sentido de conjetura o juicio ético, referido a enunciados deónticos; es al mismo tiempo una sanción en forma de atribución de inrenciones condenables a orra persona. La acusación es una sanción disfórica sobre las actuaciones de un sujeto. Se craca, por lo tanco, en el caso de la sospecha de presentar la actividad de un sujeto en la esfera de lo moral; una actividad cognitiva transitiva - no factitiva- que permanece en el universo del creer y que no actúa sobre el destinacario. La accividad del sujero que sospecha es propriocepriva y su modalidad de interacción la suspende como acción haciéndola permanecer en el universo del decir y no del hacer-hacer.

Los dos lexemas analizados en su calidad de valencias de sentido de un discurso determinado, abren la significación hacia la actualización de los contenidos, orientando esos universos semánticos hacia la expectativa o hacia la previsión de simulacros existenciales disfóricos. La densidad semántica de esos términos constituye un primer acercamiento hacia la descontrucción del texto y nos hace esperar la puesta en presencia de contenidos que pueden perrenecer al imaginario humano de cualquier cultura en cualquier momento de la historia. Este nivel temático generalizable puede ser 
cómodamente traducido de un universo de sentido a otro y de un individuo cualquiera a otro. Desde este punto de vista, podemos afirmar ya desde ahora que el interés del discurso que vamos a analizar no será el de extraer el valor de los contenidos de sus isotopías temáticas: la corrupción es un tema de rodas las culturas y cualquier individuo puede sospechar algo de alguien por muy ingenuo que sea. El descubrimiento de lo otro, que debe estar implícito en toda búsqueda semiótica, no va a provenir de lo temático, que estamos previamente proponiendo como valencia de valores y como condensación semántica por excelencia; su desarrollo en el discurso conservará, no obstante, la tensitividad fórica implícita e inmanente, ya que de todas maneras, los lexemas guardan en sus moléculas de sentido todo el poder expansivo y creador de mundos semiósicos, permitiéndonos experimentar ese poder explosivo y contaminante que es ocultado con celo, pest a nuestros esfuerzos de arrancarle sus secretos, por esa hidra de millones de cabezas constituida por los universos significantes.

La corrupción, en su condición de lexema en lengua, ha sido analizado co mo un proceso tensivo y orientado de cransformación hacia la desposesión de los objetos de valor del otro, como un aniquilamiento y un deterioro.

Por su parte la sospecha se presenta como una inestabilidad de nivel cognos citivo de parte de un sujeto paciente y observador, provocada por los progra mas deceptivos del destinador-sujero del hacer. El sujeto que sospecha posee ur no-saber inestable que lo conduce hacia la búsqueda de cercezas, pero esa ten sión cognoscitiva no puede desembocar en la conjunción con un conocimien to estable sobre el orro. Se trata también, como en el caso de la corrupción, ds un aniquilamiento de un sujeto cognoscitivo afectado en su posición de actan te-juez ético y cuyo programa de búsqueda de certezas no podrá concluir.

Esras valencias de sentido de los dos lexemas han sido puestas en discur so, y para comprender su juego significance, es necesario aprehender el text que hemos considerado previamente como sarcástico, resistente al análisis ) barroco, para someterlo al juego de los epejos analíticos y tratar de extraer d, él una cancidad imprecisa de olores esparcidos a todo to largo de la cadena ) que provienen de ese laboratorio poderoso e innovador de la instancia enun ciante y de su sujeco.

\section{Las estrategias enunciativas de un Sócrates tropical}

Como un calidoscopio el rexco comienza a girar adherido al ojo de Polifemo Un solo punto de mira para contemplar el mundo puesto en discurso y un te ma, la corrupción de lo político, como forma de vida, experiencia referencia que el sujeto de la enunciación, José-Ignacio Cabrujas, debe transformar en si mulacro a través de una praxis enunciariva que permitirá hacer llegar al lecto un tema investido de valores históricos, socializados e individualizados. 
Partir de la instancia enunciadora para hacer un análisis semiótico, en este caso, se nos impone como un recorrido iniciático, como la entrada en el laberinto de un universo de sentido que puede permitirnos palpar la alteridad cultural y la identidad de un escritor, José-Ignacio Cabrujas, director de teatro, dramaturgo y prototipo de una clase -el mejor de su especie- de los fustigadores del poder. Fallecido en 1995 , a los 58 años de edad, el papel que juega en la democracia venezolana sugiere una relación con el arqueripo socrático, con una diferencia entre otras: murió asfixiado por la cicuta de cinco paquetes de cigarrillos diarios. Estos datos, antes del análisis y fuera del texto, no son para informar a los lecrores sobre aquello que es preciso conocer para comprender, sino que se proponen como un punto de referencia para mostrar que al menos, en el caso de este autor, al mismo tiempo que nos cuenta el país, se narra a sí mismo al escribir sobre la vida política de Venezuela y describe su pathos, su pasión, como en una confesión.

A causa de la intencionalidad, podríamos decir tensa o intensa del sujeto que enuncia, el discurso pareciera resistirse al análisis o más bien se resiste a ser descrito porque pierde, de ese modo, su andadura, su tempo vital, sus efectos estéticos y su perfume irónico y pasional, que cualquier semiótico va a tener dificultad de conservar, incluso si puede lograr, en el mejor de los casos, poner en evidencia la arquicectura del texto y al menos una parte de sus mecanismos semióticos y del juego de los simulacros textuales.

Quisiéramos de esta manera plantear el problema hermenéutico del discurso sarcástico y barroco del que intentaremos dar cuenta, y que debería contaminar al mismo tiempo al analista de sospechas y de ironía sobre su propio trabajo y de algo que podría ser también interesance para la discusión: para desconstruir y reconstruir un texco, habría que añadirle a la competencia crítica del semiótico, lo sensible, lo estésico y lo pasional como un instrumento para la adecuada aprehensión de lo literario en rodos sus sentidos y en todas sus sensaciones. La estérica de la recepción tiene sus propuestas al respecto, pero en este trabajo lo tomaremos únicamente como una alusión o un deseo.

Veinte en conducta, discurso al que hemos llamado barroco, se presenta como una entidad semiótica heterogénea: en primer lugar el género epistolar. después el estilo conversacional, más tarde el discurso retórico argumentativo y poético, en fin, la modalidad irónica del texto. Si tomamos la escritura de Cabrujas como intricada, basta con consignar estas primeras articulaciones en el momento de plantearnos el abordaje analítico, para poder demostrar la convivencia de varias entidades semióticas heterogéneas, las sobredererminaciones y la densidad de estrategias plurales de la instancia de la enunciación, que van abriendo aś los caminos de la distancia y de los laberintos de la escritura en el bricolaje de los signos como figura impuesta por el discurso moralizador. Distancia manifestada por la polifonia de voces instauradas en el texto y que Cabrujas organiza como en un baile de máscaras para esconderse y ser $e l$ mismo 
y los ottos, distancia y giro paradójico del decir, propio del discurso humoristico $y$, en fin, distancia también del discurso rerórico que adquiere su eficacia de la palabra misma como objeto , gracias a los recursos estéticos y a la capacidad manipulatoria -al poder del verbo- que alcanza su blanco a partir del punto de disparo a través de los laberintos significantes.

\subsection{CARTA ABIERTA AL PRESIDENTE DE LA REPÚBLICA}

La primera elección del sujeto de la enunciación es la de instalar un tú que es en realidad otro tratado de usted; manipulación seductora y eficaz de la comunicación en el más directo de los estilos de la vida cotidiana :

Para serle franco, Presidente, nunca imaginé esa disculpa, ese borrón y cuenta nueva con el que su generosidad, a falta de mejor palabra, subsana viejas heridas. Porque, digámoslo de una vez, quien agiró el fanrasma del Sierra Nevada en los días de la campaña interna, quien expulsó de la administración pública a aquellos funcionarios que disentlan del candidato oficial, quien $k$ dio vela y muerto a la bienamada a fin de preparar el guiso que favorecia al doctor Lepage, aún a cosra de llamarlo a usted ladrón. quien puso en el capete, mediante avisos de páginas completas financiados a punta de erario el veredicto del Tribunal de Ética en contra suya, fue el mismo pediatra al que usted ahora exonera, aureola, avala y hasta exhibe como un ejemplo de nírida honradez ciudada. na. (Cabrujas, 1992, p. 134).

Ese "Para serle franco, Presidente..." del orador, transgrede en un tempo insólito todas las normas de cortesía que regulan los inrercambios comunicativos sociales $^{2}$ y convoca a un simulacro provocador. Manipulación por seducción dirigida de hecho al auditorio ${ }^{3}$, a los lectores. Esta estrategia enunciariva conscituye una isotopía de nivel discursivo y regula la coherencia del texto desde su inicio hasta el final. Sus consecuencias significantes convocan diversos valores comunicativos implícitos.

Por el hecho de tratarse de un simulacro del género epistolar -carta abierta- produce una simulación de contrato fiduciario garante del intercambio comunicativo eficaz y presupone una intimidad cómplice entre los corresponsales de la carta. Evoca, al mismo tiempo, el valor mítico de las Epistolas dirigidas en el universo de lo sagrado a los fieles para sostenerlos y para convencerlos al entrar en comunión con el otro. Este mecanismo simula la realidad de la comunicación epistolar en la que , el que escribe una carta, aguarda la respuesta de un corresponsal que en este caso preciso será, sin embargo, una sombra de actante (Panier, 1996): ni el Presidence instalado en el discurso, interlocutor explícico, ni el destinatario social implícito serán convocados en este caso a participar para responder a la carra.

El enunciador construye de esta manera una figura referencializada en el sentido de que el Presidence Pérez es el Presidente Pérez de un mundo real. pero no es su verdadero corresponsal en una carta simulada en su manifestacion discursiva. De esta manera el texto establece una primera distancia pre- 
sentándose como lo que no es, buscando, sin embargo, a través de esa estrategia su eficacia comunicariva. El juego del simulacro epistolar y conversacional cotidiano convoca al verdadero destinatario, el actante social, a participar en un intercambio junto con un yo-portavoz de la opinión pública- que adquiere de este modo acceso al universo del poder, logrando hacer bajar a la calle para ponerlo al alcance de todo el mundo, al Senor Presidente de la República.

La anulación de la distancia entre el Destinador del Poder y sus destinatarios -los lecrores de la prensa del pueblo venezolano- por medio del simulacro instalado por la instancia de la enunciación, puede lograrse únicamente gracias a la mediación semiótica que crea de esta manera un universo imaginario: una apariencia de carta, con una apariencia de corresponsal y una apariencia de acercamiento comunicativo de estilo conversacional, frence a los acontecimientos referenciales de la vida política.

Desde el punco de vista de la retórica semántica ese "Para serle franco, Presidente..." gracias a un juego anrifrásrico paradójico, equilibra las posiciones de estructura profunda dominante/dominado que subyacen en el discurso del poder, para instalar dos actantes con funciones y posiciones simétricas en tanto que corresponsables de la comunicación. Este artefacto constituye ya, por sí mismo, una suerte de micro-escena de la vida cotidiana republicana, de un estilo de vida venezolano, al evocar cualquier tipo de encuentro en cualquier momento de la convivencia social entre las gentes.

Al mismo tiempo el discurso enunciante, el discurso gerenciado desde ese lugar privilegiado, se instaura como la palabra capaz de consticuir un universo de valores soberanos. El orador, José-Ignacio Cabrujas, alcanza su blanco y el Presidente no detentará ya el poder en el universo de la palabra ética y estérica. Desposeído de su voz quedará sometido a todo lo largo del texto al silencio. A partir de esa apelación que explicita el decir direcro y claro-el decir verdadero- de un enunciador que toma la palabra como Maescro de la Comunicación, eliminando en su simulacro la presencia del otro, Carlos Andrés Pérez, que deberá permanecer únicamente como una sombra de actante enunciativo.

\subsection{EL SUJETO DE LA ENUNCIACION, DIRECTOR DE TEATRO}

La tensión de la instancia enunciativa produce un discurso intenso (Greimas y Fontanille, 1991). Hemos mostrado el juego de posibilidades significantes del género epistolar, su poder de evocación de lo mítico, de lo comunicacivo y su poder de simulación para lograr su eficacia manipulatoria. Pero si por un lado se instala un yo frente a un usted isótopos, que garantizan la coherencia y que enuncian, al mismo tiempo, la primera esquicia del sujeto, vemos también como esta esquicia escalla $y$ pone en presencia varios actores del discurso que van a tener a su vez derecho de palabra: 
¿Será Lusinchi un ladrón. Presidente? Créame que rengo años con esa pregunta en la cabeza, sin decidir mi concepción íntima, tocalmente innecesaria en un tribunal, pero al mismo tiempo imprescindible para entenderme a mi mismo. Porque en el fondo se trata de eso, se trata de vivir y comprender dónde vives, hasta dónde hemos llegado y qué se espera de nuestra crónica. Es por eso que importa saber si el doctor Lusinchi es un corrupro y no por otra razón. No para solazarnos en la figura del manipulado, del tonto insrigado por una cotona, del figurón que se derrumba para convertirse en simple escarnio de botiquín. No hay triunfadores en el veredicto. No se traca de una sencencia que pueda complacernos. Por el contrario sería una terrible vergüenza asumir que durante cinco años, los venezolanos fuimos estafados por un Pomponio de aspecro bonachón y mirada dulzona, invadido por la picaresca y el desgano. No hay manja más esrúpida ni sentimiento más mediocre que reducir nuestra política a la altura del tercer whisky, a una cáfila de sinvergüenzas que saquean el tesoro público; no hay peor mirada en el sentido de danina mirada, que esos ojitos entrecerrados en la barra de un restausante gallego, cuando tu interlocutor concentra sus palabras y dice sin el menor retroceso: ¡es que esca vaina se jodió! ¡Es que este país hay que esconderlo! ¡Es que todos son una cáfila de delincuentes! Tenemos años y años, revolcándonos en esa mierda, señor Presidente, años complaciéndonos en hallazgos, en columnas chismosas, teléfonos intervenidos, documentos fotocopiados, anegados hasta el cogote en la sensación de vivir un desastre (...) Y como no hay ley, como los rribunales no sirven para nada, ese tejido de impotencias ciudadanas, de asco cívico, nos ha conducido a la amargura (Cabrujas, 1992, p. 134).

Al poner en práctica esta estrategia podremos observar cómo se opera una transformación en el enunciador, que ya no va a aparecer, a partir desde ese momenro, como el único responsable de su propio discurso al convertirse en el-mismo y los otros, actante social e individual al mismo riempo. Este oculamiento logrado a través del otro-colectivo actúa como operador de una transformación que lo convierte en portavoz de la opinión pública; este nuevo rol lo califica para la realización de su programa narrativo de base como fustigador de los vicios del poder $y$, al mismo tiempo, lo protege como sujero jurídico individual, liberándolo de sus responsabilidades legales ante lo dicho y por lo tanto de los problemas penales que le podrían acarrear la audacia de sus aserciones.

Su yo se multiplica por un lado como un sujeto de la enunciación; otro ego se desdobla en la realización de un simulacro de diálogo interior, proponiéndose -cual Hamlet- como sujeto en busca de verdades o certezas en la esfera de lo político, ya que la ruptura del contrato social ético ocasiona un recorrido rensivo-fórico, que a causa de los acontecimientos exteroceptivos contamina la propioceprividad del sujeto. Los sencimientos interjores del yo en contacto con los acontecimientos políticos de los que es testigo y juez hacen que sienta una amenaza a causa de las transformaciones disfóricas -negativas- de la esfera de lo moral y que lo afecran tanto desde el punco de vista de su presencia en la esfera de lo social como en su integridad individual.

Una forma de vida que golpea sus convicciones más íntimas sobre su saber y su hacer de cronisca del acontecer político: para poder juzgar y acruar 
en su rol de acrante-juez supremo es preciso primero conocer -estar provisto de un saber- acerca del recorrido moral de lo sancionado.

En otra secuencia retoma el mismo tipo de simulacro:

Entonces, ¿qué es lo que me pasa, señor Presidente, con Jaime Lusinchi? ¿de verdad lo acuso de algo? ¿rengo en mi poder alguna prucba no consignada en la comisión que investiga sus dlas en Miraflores? (Cabrujas, 1992, p. 134).

El silencio al cual el Destinador de la Palabra ha condenado al Destinador del Poder, restituye el juego de la omnipotencia de la instancia enunciante y por la repetición de ese mecanismo refuerza ese otro carâcter de su discurso manifestado como una confesión de la confusión, cuya intencionalidad primera -su objetivo- es la de confundir al traidor.

Por otro lado $-y$ es preciso ahora recordar al sujeto tensivo de la enunciación- el yo se desliza hacia un nosorros en el despliegue sintagmático de la cadena escrita. Este cambio no aparece marcado en el texto por ningún carăcter formal previo. El actante colectivo tiene acceso de este modo al discurso, convocado por el estado tensivo de J.I.Cabrujas, por sus valencias actanciales existenciales que lo sirúan como uno y como todos al mismo tiempo.

En la secuencia citada más arriba, el pronombre personal se convierte en un impersonal; el yo-mismo se aleja y se mariza gracias a: porque se trata de eso. Se trata de vivir... La aspectualización del paradigma pronominal que a nivel semántico comporta una relación de lo intensivo del ego, a lo extensivo del $t u, e l$, ustedes, ellos, está en la base de ese deslizamiento de los valores semánticos y comunicativos. Asl es como se pasa del impersonal intensivo hacia nosotros, extensivo, pero plural y personal.

El cambio se realiza de esta manera y el actante social ocupa la escena como el coro del teatro griego en el que la polifonía de voces se concentra en la figura del corifeo (Landowski, 1989) para participar en la sanción sobre la corrupción política. Este actante enunciativo recibe sus competencias del enunciador, Descinador Supremo de su discurso, aunque siga permaneciendo bajo la forma de simulacro o sombra actancial que, paradójicamente, otorga sus valores al actante individual de la enunciación. Para el portavoz de la opinión pública es esca una estrategia de adquisición de poder y una manera de compartir las responsabilidades de sus propias aserciones en esce enfrentamiento furibundo: ese nosotros, que tiene acceso a la inscancia de la sanción, es la figurativización del país, de todos los venezolanos.

Pero hemos anunciado que José-Ignacio Cabrujas era dramaturgo y director de reatro, y su discurso conserva siempre las huellas -por una suerte de deformación profesional inevicable- de su poder de lograr que el mundo actúe. De este modo, la multiplicidad de movimientos organizados desde la instancia de la enunciación, le permiten poner en escena -a lo largo del hilo sintagmático de su crónica- un texto polifónico y barroco. en el cual las voces, puestas ya en evidencia a partir de la instancia que dirige el discurso, se mul- 
tiplican en otros actores sociales y componen en un tempo vertiginoso, un collage de los acontecimientos de la vida republicana con un juego de simulaciones que evocan micro-escenas de la vida cotidiana, dramatizadas y paródicas, y que son, al mismo tiempo, formas de vida y universos de valores. Identificándose con esta praxis enunciativa el enunciatario implíciro-lectorpodrá encontrar el recuerdo y los ecos de lo vivido cocidianamence en los bares y en la calle y de su experiencia referencializada de la descomposición continua de lo político.

Hasta ahora nos hemos acercado sólo al texto, a su arquitectura, desde el punto de vista de su simulacro enunciativo sin agotarlo. Esta actividad nos ha permitido, entre otras cosas, reforzar nuestros temores iniciales de no saber muy bien cómo sobrevolar primero el discurso, para sumergirnos después en las profundidades de lo semiótico.

\section{Convivencia en el discurso de diversas entidades heterogénea}

Este texto con sus laberincos y sus entidades heterogéneas, consricuidas en bricolaje de signos, como acertadamente y siguiendo a Lévi-Strauss los llama Jean-Marie Floch (1995) ${ }^{4}$ es rambién, y desde orro punto de vista, una pieza oratoria que sigue las reglas de la Antigua Retórica argumentativa remodelada. Escrita para convencer y para complacer al auditorio, está hecha también para fusrigar los vicios del poder, acusando y condenando, para provocar al otro.

Discurso ético y estético, su intencionalidad moralizadora y argumentativa se manifestará a través de diferentes modalizaciones manipulatorias. Sus valores pasionales, sensibles o estéticos se articulan por medio de los recursos de la retórica figurativa, principalmente gracias a los efectos de ironía que perfuman todo el texto. Una ironía sensibilizada y pasionalizada y por lo canto tensiva que sigue un recorrido aspectualizado y cualitativamente ascendente para transformarse. después de pasar por el esrado de amargura, en sarcasmo, esa agrura tímica y somática que producen los humores deceprivos de aquello que está demasiado corrompido.

Desde el punto de vista de la retórica argumentativa podríamos segmencar esce discurso de una manera casi canónica y reconocer las diferentes partes de la dispositio: exordio, narratio, argumentatio y peroratio, con sus finalidades persuasivas, pero una vez dicho esto. nos parecería una actividad un poco ociosa en relación con un rexto que nos obliga a dar cuenta más bien de los universos semánticos enunciados, que deben ser extraídos de la profundidad de sus articulaciones.

Son los juegos y la intricación de las estructuras modales, los responsables de la construcción isotopante de un discurso que sanciona y aserta la 
valoración disfórica y deceptiva, manifestándose como una configuración modal de la incerridumbre convertida en la pasión de la sospecha. Es así como se construye en las estructuras rextuales ya que el discurso evidencia la incertidumbre epistémica -el no-creer ser-es decir lo inverosímil. Pero no olvidemos que la actividad intensa del sujeto de la enunciación que simula la sospecha para aseverar la certeza, mantiene abierta sobre todo, a lo largo de la cadena sintagmática, la instancia enunciante $y$ produce su simulacro ético condenatorio con un juego vertiginoso de embragues y desembragues. La mulciplicidad de programas $y$ sub-programas narsativos está condensada gracias a un juego de implicaciones y presuposiciones que da lugar a operaciones de inferencia, para que la expansión discursiva, a expensas de la condensación narrativa, permitan el cumplimiento de la intencionalidad escética e irónica del orador.

En lo que se refiere, por lo tanto, a la puesta en discurso de las configuraciones modales del enunciador $y$ de los actantes enunciados para compartir su pathos oracular, el tempo es tan vivo que a un trayecto modal de incertidumbre lo sucede un estado de creencia, que se convierte en sospecha a instancias de la actividad veredictoria del actante en su propioceptividad, provocado todo ello, por los acontecimientos referenciales de esta historia de vida venezolana. Estas transformaciones de estado modales y pasionales de los sujetos enunciados, se despliegan en el nivel textual por medio de micro-secuencias condensadas, que desafían la amplitud de los escenarios espacio-temporales y sociales y la envergadura de los simulacros existenciales puestos en escena: una forma de vida, una visión del mundo, una cultura puesta en discurso en las tres breves páginas de una crónica periodística semanal, pueden por sl solas, permitirnos cumplir con uno de los objetivos de mostrar la arquitectura de la significación.

Pero ¿qué sucede con el discurso sarcástico? La ironía le sirve de figura retórica dicursivizada a todo to largo del texto, y le permite articularse siguiendo un trayecto aspectual intensificador, para manifestarse a partir de la conjunción de los sujetos con la amargura. El sarcasmo procede del nivel discursivo y se construye, como la ironía, acogido por las figuras retóricas: paradojas, antítesis, hipérboles, litotes y, de manera destacada en este texto, por la distancia antirética entre el nivel de lenguaje de las hablas conversacionales coridianas y el otro discurso, el del que denuncia -moralizador de la vida política y social- incrustados el uno en el otro y también disociados, desde la misma y única voz del discurso enunciante y enunciado. Es esra, sobre todo, la gran estrategia de la distancia socrática de Cabrujas. 


\section{Aseverar sospechando: estrategia manipulatoria del iro- nista que habla en nombre del Otro}

Para ser uno-mismo y los-otros, para ser el oráculo o el portavoz de una pluralidad dispersa y decepcionada, para inscribir en la hiscoria de un país el discurso de la denuncia y de la amargura, es necesario poseer competencias comunicativas arquerípicas para no correr el riesgo, si no, de decir lo ya dicho y lo ya sabido. Para no correr el peligro de convertirse en un estereoripo es preciso ser creador de un universo de lenguaje. El poder, a fuerza de serlo y de actuar con una performatividad que le es intrínseca, llega a ejercerse impunemente $y$ a desnaturalizarse por la fuerza misma de su ejercicio desviante. Los accores del poder político antes de ser servidores de la res publica, deben adquirir una competencia que no puede ser transmitida sin ser desperdiciada, al mismo ciempo. Y la estrategia de su ejercicio se anuda en una serie de contratos polémicos donde el anti-sujeto busca, precisamente, el mismo objeto del opositor que actúa para perjudicar al otro. Esta banalización enunciada sobre los juegos que se ejercen a través del contrato social, es propuesta únicamente a guisa de preámbulo, para poder resaltar la construcción de un actor social investido de poder en otra dimensión: aquella en la que el saber puede dar acceso a la instancia del juicio ético para convertir así al sujeto cognitivo en Actante Juez Supremo.

El investimiento de ese sujero como orador no proviene de un contrato polémico para la adquisición de poder y las comperencias necesarias para el ejercicio de su rol social no se realizan, como para los actantes del poder, en una serie de enfrentamiencos continuos a causa de lo adquirido y de su pérdida. El portavoz de la opinión pública, ese oráculo de los dioses, es su propio Destinador y su territorio de actuaciones frente al poder es únicamence semiósico. Pertenece al mundo de la mediación entre lo real y lo psico-social. Este accor que es la voz del otro, actúa en solicario en nombre de los demás y su deber-ser, su modalidad dé́ntica, es la de transformar lo inteligible en sensible. Solamente la construcción de un simulacro estético y esrésico, le permitirán realizar su quehacer cognitivo para elevarse de esta manera, en nombre de Todos, por encima de la dimensión pragmárica. Chamán oracular, tomará sobre sí mismo la responsabilidad social de voz que clama en el desierto. Esce Senor de los Espacios de lo semiótico decenta su poder, frente al otro poder, gobernando con coda libertad la instancia enunciante y manipulando el enunciado que se convertirá en espectáculo recreador y rerapéutico para el actante colectivo. Como ya hemos anunciado, la ironía, las estrategias manipulacorias persuasivas, las figuras retóricas -espacios superiores del lenguaje- son puestas en discurso para cumplir con esa misión y alcanzar la eficacia comunicariva.

Veinte en conducta se presenta como un topoi ideal para la observación de las estrategias semióticas de la instancia de la enunciación que gracias a la praxis 
enunciativa manifiesta los valores y las axiologías de una sociedad dada en un momento determinado de su historia. Adernás de los juegos de la instancia de la enunciación y de su polifonja barroca, a lo largo de toda la rrama discursiva, se articula una estrategia argumentativa y persuasiva que recorre el rexto bajo la forma de la modalidad paradójica de la aserción -sanción contra el poder corrompido-que se manifiesta en el discurso como sospecha, como preguntas que esperan una respuesta, como duda o perplejidad, estados modales pathemizados todos, que provienen de una búsqueda de certezas simulada para poder aseverar las convicciones. Por último, la ironía y su intensificación cualitativa, el sarcasmo, se construyen en el discurso como formas continuas aspectualizadas de cuya delimitación formal, no es responsable ni una figura retórica determinada, ni una modalidad enunciativa, ni el juego de voces orquestado desde la instancia que maneja el discurso, sino codos esos juegos continuos y discontinuos al mismo tiempo, de los que la entrerejida trama de un texto semánticamente denso, es manifestación perceptible y sensible.

NOTAS

1. Con este trabajo iniciamos el micro-análisis de un artículo de José-Ignacio Cabrujas (dramaturgo, guionista de cine y televisión y cronista de prensa venezolano. 1937-1995), Veinte en conducta, publicado en El Diario de Caracas el 20 de octubre de 1991 y recogido después en una recopilación de todos sus artículos de opinión aparecidos en ese periódico por la Edirorial Monce Ávila en coedición con $E l$ Diario de Caracas. Entre orros aspectos importantes, en este texto resume Cabrujas sus reflexiones sobre un periodo de la democracia venezolana que va de 1973, año en que se inicia el primer mandaro de Carlos Andrés Pérez, hasta 1991, año en que, después del gobierno de Jaime Lusinchi (1993-1998) Pérez está en la mitad de su segundo periodo constitucional.

2. La bibliografia sobre este tema es hoy extensísima; remitimos a C. Kerbrat-Orecchioni : Les interactions verbales I, II y III de la editorial francesa Armand Colin (1990-1995).

3. Las crónicas semanales de Cabrujas aparecían los domingos y sus leccores cautivos esperaban sus escritos para mirarse en su espejo. Considerado como un auténtico portavoz de la opinión pública de la clase profesional e intelecrual venezolana, producfa uno de esos efectos que tanto interesan a la estécica de la tecepción: ninguno de sus trabajos podía pasar inadvercido y permitía la identificación no sólo del lecior con el auror, sino de los lecrores enire ellos; era un rema de conversación obligado entre pares todos los domingos.

4. El concepto de bricolage lo uriliza Floch relacionado con objetos semióricos visuales; la extensión mecafórica del término, aplicada en esre caso a un discurso escrito, se refiere a la pertenencia de este discurso a diversos géneros: periodistico, polírico, humorístico, retórico... El problema de las cipologías de los géneros, que esrimuló hace muchos años a los estudiosos del discurso, no hace sino replanrearse en cada giro del calidoscopio, y en relación con los discursos de opinión de José-lgnacio Cabrujas, no podemos sino permanecer en el intersticio tipológico. 
Cabrujas, J.J. (1993). El pats según Cabrujas. Caracas: Monte Avila.

Delorme, J. (1987). Parole, figure et parabole. Lyon: PUL.

Espar, T. (1995). El relato oral como discurso mediador entre este mundo y la otra orilla. Escritos, 11-12,113-130.

ESPAR, T. (1998). La semiótica y el discurso literario latinoamericano. Caracas: Monre Avila.

FLOCH, J.M. (1995). Identités visuelles. París: PUF.

FonTANILLE, J. (1995). Sémiotique du visible. París: PUF.

FOnTANille, J. (1996). Ponencia realizada en Colloque sur l'Enonciacion dans la lettre. Lyon: Cadir.

Greimas, A. J. (1966). Sémantique Structurale. París: Larousse.

Greimas, A. J. (1989). De limperfection. Périgucux: Faniac.

Greimas, A. J. y COURTÉs, J. (1979) Semiotique. Dictionnatre raisonné de la théorie du langage. Paris: Hacherte.

Greimas, A. J. y COUkTES, J. (1986). Sémiotique. Dictionnatre raisonné de la thérie du langage. ( $2^{\circ}$ ed.). París: Hachette.

Greimas, A. J. y Fontanille, J. (1991). Semiotique des passions. París: Seuil.

Jankélevitch, V. (1964). Lironie. París: flammarion.

LANDOWSK, E. (1989). La societe reflechie. París: Scuil.

Oliveira, A.C. DE Y LANDOWSKY, E. (1945). Do intelgyivel ao sensivel. Sao Paulo: EDUC.

Panier, L. (1996). Au sujet de la lettre. Ponencia realizada en Colloque sur l'énonciation dans la lettre. Lyon: Cadir.

Pozuelo, J. M. (1992). Teoria del lenguaje literario. Madrid: Cácedra.

Quemada, B. (1993). Greimas lexicologue. N.A.S. 25, Hommages à Greimas. Limoges: Putim.

RASTIER, F. ( 1991). Sémantique et recherches cognitives. París: PUF.

Rucoeur, P. (1990). Soi-même comme un autre. París: Seuil.

Vernant, D. (1997). Du discours à l'action. París: PUF.

WittgensteIn, L. (1953). Philosophical investigations. Oxford: Basil Blackwell

TERESA ESPAR es profesora titular de la Universidad de Los Andes (Mérida. Venezuela), donde se ha desempeñado como docente e invescigadora desde 1975. Invesriga principalmente en las áreas de la Semiótica y la Lingüística del Discurso y coordina desde 1982 el Grupo de Investigaciones Semiolingüísticas (Gis). Ha publicado diversos articulos en revistas especializadas de Venezucla y ocros paises. Entre sus publicaciones más recientes, pueden destacarse las siguientes: El relaro oral como discurso mediador entre este mundo y la orra orilla (1996), Escritos, //-12, 113-130, Puebla, México; El discurso o la polifonía de un término (1996), Leng'tua y Habla, 2, pp. 56-55, ULA, Venezuela; El aspecro como puesta en perspecriva del discurso (1997), Letras, 3, pp. 5-16, UCAB, Venezuela; Para un análisis scmio-lingüístico del devenir (1997), Filosofia, 9-10, pp. 253-268, Mérida, Venezuela; La semiótica y el discurso literario Latinoamericano (1998), Caracas: Montc Avila Editores, 198 pp. Correo electrónico: terenest@cantv.net. 